\title{
Distribution of Doublecortin Immunoreactivities in Developing Chick Retina
}

\author{
Younghwa Kim*, Woong Sun ${ }^{1}$ \\ Department of Emergency Medical Technology, College of Public Health Science, Kyungil University, Gyeongsan 712-701, Korea \\ ${ }^{1}$ Department of Anatomy, Division of Brain Korea 21, Biomedical Science, Korea University College of Medicine,
}

Seoul 136-701, Korea

*Correspondence to:

$\operatorname{Kim} Y$,

Tel: $+82-53-850-7509$

Fax: +82-53-850-7509

E-mail: yhkim01@kiu.ac.kr

Received August 17, 2012

Revised September 8, 2012

Accepted September 10, 2012
Doublecortin (DCX) is a microtuble-associated protein that is required for the migration of immature neuroblasts within the chick and mammalian brain. Although it is generally thought that DCX is expressed only in the neuroblasts, some mature neurons maintain DCX expression; for example, horizontal cells in adult rat retina. In this study, we demonstrate that retinal neural progenitors in the early embryonic stage of the chick also expressed DCX, as do developing ganglion cells and horizontal cells in later stages of development. These findings raise the possibility of a role for DCX in retinal neural progenitors, before they become specialized into neuroblasts in the chick.

Key Words: Chick embryo, Doublecortin, Retina, Stem cells

\section{INTRODUCTION}

Doublecortin (DCX) encodes a $40-\mathrm{kD}$ protein, which promotes microtubule stabilization (Francis et al., 1999; Gleeson et al., 1999). The importance of DCX in neuronal migration has been clearly demonstrated by the finding that mutations of DCX cause human X-linked lissencephaly and double cortex syndrome (Gleeson et al., 1998; Sossey-Alaoui et al., 1998). Consistent with this proposed function, DCX is highly expressed in migrating neuroblasts in the developing mammalian brain (Hannan et al., 1999). Because DCX expression is predominantly observed in neuroblasts, it has been widely used experimentally as a marker of migrating neuroblasts (Francis et al., 1999; Gleeson et al., 1999). In particular, DCX has been actively utilized as a marker for neuroblasts in adult neurogenic regions. However, several exceptions were recently reported. Some cells, in the piriform cortex and suprachiasmatic nuclei of the adult rat brain also exhibited DCX expression (Nacher et al., 2001; Geoghegan \& Carter, 2008). These DCX expressing cells are morphologically mature and they do not proliferate, indicating that certain mature neurons may also express DCX (Engelhardt et al., 2005). Furthermore, DCX expressing cells can differentiate into oligodendrocytes following brain injury (Weiss et al., 1996; Seaberg \& van der Kooy, 2003). Taken together, these findings indicate that DCX may play an important role in these non-neuroblast cells. In the chick, expression of DCX in the developing brain has been explored previously, and the dominant expression of DCX in the immature neuroblasts was found to be conserved (Hannan et al., 1999).

The retina is derived from developing brain tissue, and thus retinal development has been widely used as a model for central nervous system development and histogenesis (Wakabayashi et al., 2008). The retina is composed of 6 cell types; photoreceptors, amacrine cells, bipolar cells, horizontal cells, ganglion cells and Muller glia. All of these cells are derived from retinal stem cells, and their genesis is sequentially regulated. Horizontal and ganglion cells are the earliest cells to differntiate from multipotent retinal stem cells, and photoreceptors are born later (Turner et al.,

This research was supported by Basic Science Research Program through the National Research Foundation of Korea (NRF) funded by the Ministry of Education, Science and Technology (2012-0004004).

(a) This is an open-access article distributed under the terms of the Creative Commons Attribution Non-Commercial License (http://creativecommons.org/licenses/by-nc/3.0) which permits unrestricted noncommercial use, distribution, and reproduction in any medium, provided the original work is properly cited.

Copyrights (C 2012 by Korean Society of Microscopy 
1987; Rapaport et al., 2004). In the developing retina, DCX expression has been explored. For example, in the rat, DCX is preferentially expressed in immature ganglion cells and horizontal cells, but is not found in other cell types (Lee et al., 2003). Furthermore, DCX expression in horizontal cells was maintained into adulthood, suggesting that DCX in the retina may not be a suitable marker for immature neuroblasts (Wakabayashi et al., 2008). To extend our knowledge of the possible role of DCX in the retina, we investigated DCX expression patterns in the developing chick retina. Chick has been widely used as a model for retinal development, because of the easy access to early embryonic tissues via eggshell opening and the relatively large size of the retina (Capes-Davis et al., 2005). Interestingly, we found that DCX is expressed in the neural progenitors before the specification of neuroblasts. Our current observations suggest a potential role of DCX in neural progenitors.

\section{MATERIALS AND METHODS}

\section{Chick Embryos}

Fertilized eggs (Pulmuone, EumSeong, Korea) were incubated at $38^{\circ} \mathrm{C}$ in the humidified incubate for indicated time.

\section{Tissue Preparation}

Embryos were isolated from extraembryonic tissues and immersion-fixed in 4\% paraformaldehyde for 3 6 hrs at room temperature (RT). Next, embryos were transferred to $30 \%$ sucrose solution for cryoprotection. When embryos sunk in the solution, whole embryo (E3) or isolated eyes (E12) were frozen embedded in the optimal cutting temperature compound. Eye tissues were then cut $(12 \mu \mathrm{m})$ coronally on a cryostat. The sections were then attached onto the coated slides and stored at $-70^{\circ} \mathrm{C}$ until use.

Table 1. Antibodies used in this study

\begin{tabular}{llll}
\hline \multicolumn{1}{c}{ Antibodies } & Origin & \multicolumn{1}{c}{ Titer } & \multicolumn{1}{c}{ Source } \\
\hline DCX & Goat & $1: 200$ & SantaCruz \\
Pax6 & Mouse & $1: 1,000$ & \\
Islet 1 & Mouse & $1: 100$ & Hybridoma Bank \\
Tuj 1 & Mouse & $1: 1,000$ & Sigma \\
Neu N & Mouse & $1: 1,000$ & Milipore \\
Map 2 & Mouse & $1: 1,000$ & Milipore \\
Anti-goat Alexa 555 & & & \\
Conjugated IgG & Donkey & $1: 1,000$ & Milipore \\
Anti-mouse Alexa 488 & & & \\
Conjugated IgG & Donkey & $1: 1,000$ & Milipore \\
\hline
\end{tabular}

DCX, doublecortin; Pax6, paired box gene 6; Tuj1, class III beta -tubulin; MAP2, microtubule-associated protein 2.

\section{Immunohistochemistry}

Slides were thoroughly dried, and incubated with blocking solution containing $3 \%$ bovine serum albumin and $0.1 \%$ Triton X-100 in phosphate buffered saline (PBS), for $30 \mathrm{~min}$ at RT. Next, primary antibodies were applied for the $12 \mathrm{hrs}$ at RT. The list of primary antibody used in this study is shown in Table 1. Sections were then washed with PBS 3 times, and appropriate secondary antibodies were applied for 30 min. Nuclei were counter stained with Hoechst33342 for 5 $\mathrm{min}$, and the sections were washed, mounted and examined under a confocal microscopy (LSM510; Zeiss, Goethingen, Germany).

\section{RESULTS}

\section{Developmental Changes in the Expression of DCX in the Chick Retina}

First, we examined DCX-immunoreactivity on E3, E4, E6, and E8 chick retina (Fig. 1). Although we predicted that DCX immunoreactive cells would be enriched on E6 E8 when immature neuroblasts are specified, we found that E3 retina showed the strongest and most widespread DCX immunoreactivity (Fig. 1A). On E3, strong DCX expression was evident across most cells in the central retina, except for the most peripheral parts of the eyecup. However, by E4, cells in the innermost layer (primitive ganglion cell layer) exhibited strong DCX immunoreactivities, but cells in other layers were comparatively weakly labeled. DCX signals were also found in
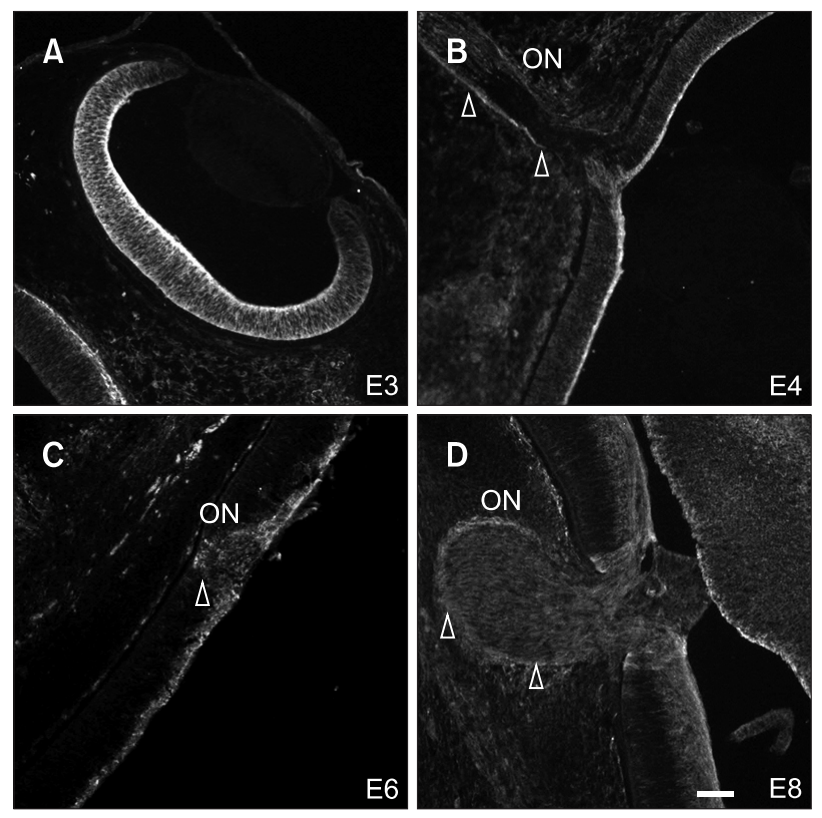

Fig. 1. Expression of doublecortin (DCX) on E3 (A), E4 (B), E6 (C), and E8 (D) chick retina. Optic nerve head (ON) was indicted by arrows. Scale Bar $=50 \mu \mathrm{m}$. 
the optic nerve, suggesting that DCX is expressed in immature ganglion cells, and in their centrally projecting axons (Fig. 1BD).

\section{Distribution of DCX Immunoreactivity in the Neural Progenitors on Early Embryonic Chick Retina}

To further characterize the cells expressing DCX on E3 retina, double immunofluorescent labeling of DCX with Pax6, a marker for retinal stem progenitor, Islet 1 , ganglion cells, and Tuj 1, a marker for post mitotic ganglion cells was performed (Fig. 2).

Pax6 expression was found in the most peripheral retinal cells, a subset of the innermost cells in the central retina, and the retinal pigmented epithelial cells (RPE) (Fig. 2A-C). Because DCX expression was present in the entire central and proximal peripheral retina, a large portion of Pax6-expressing cells were double-labeled with DCX. The other hand Pax6 expressing RPE cells never labeled with DCX.

Islet 1 labels ganglion cells, and Islet-expressing cells were found in the subset of DCX positive innermost layer cells in the central retina (Fig. 2D and F). Therefore, in addition to these early-borne ganglion cells, many other retinal cells at this stage express DCX. A similar result was observed with double staining for DCX and Tuj 1, which labels ganglion cells (Fig. 2G-I). Taken together, these results indicate that retinal neural progenitors also express DCX in the chick retina, prior to differentiation into neuroblasts.

\section{Distribution of DCX in the Granule Cells and Horizontal Cells in E12 Chick Retina}

To evaluate the distribution of DCX on later chick retina, we next examined the localization of DCX by double labeling with Islet 1 and Tuj 1, two ganglion cell markers (Fig. 3). As previously shown in developing rat retina, DCXimmunoreactivity was strong in the ganglion cell layer and the inner plexiform layer (IPL), which is enriched with granule cells and other cell's synapse. Furthermore, DCX-expressing cells were strongly labeled by Tuj 1. Interestingly, Tuj 1-labeled optic fibers were also strongly labeled with DCX, but signals of the two proteins in the IPL were not strongly co-localized. Considering that many cells localized at the inner nuclear layer (INL) expressed DCX while their Tuj 1 labeling was only
Pax 6/DCX
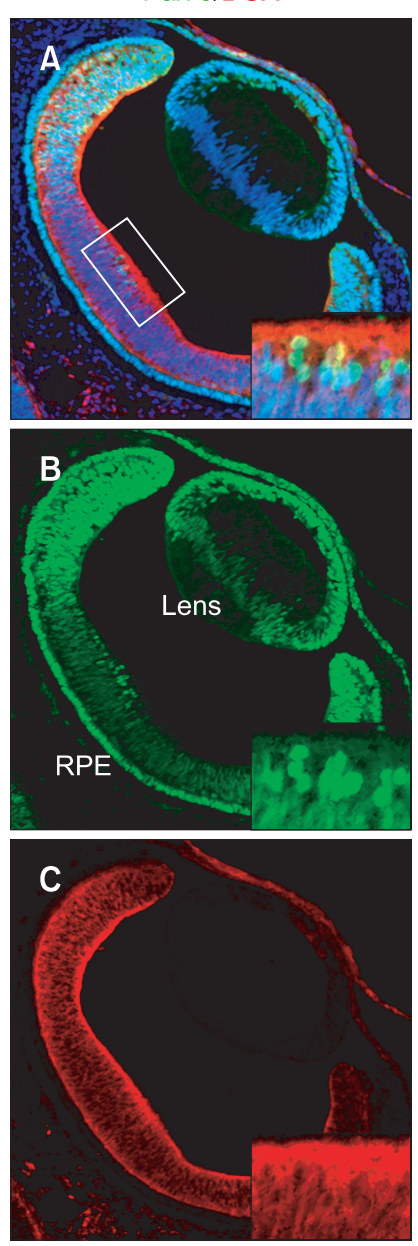

Islet 1/DCX
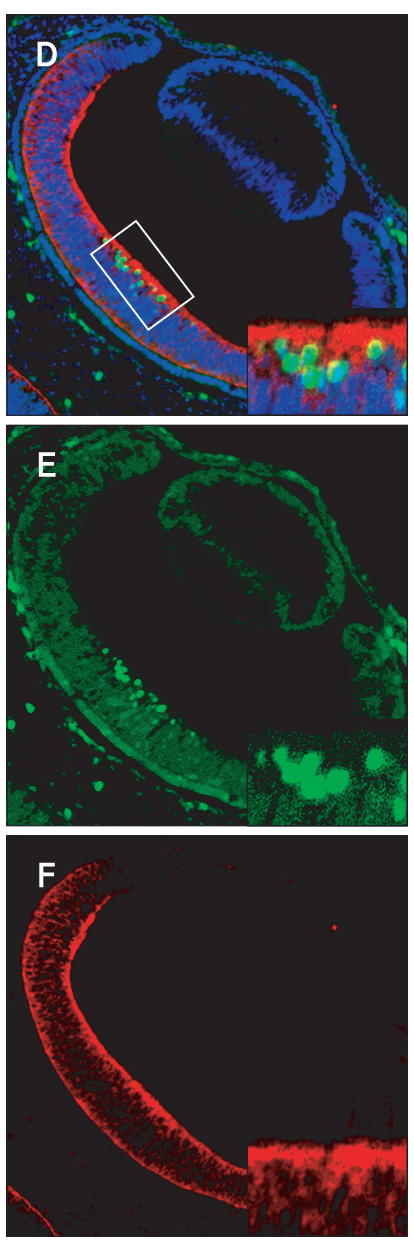

Tuj 1/DCX
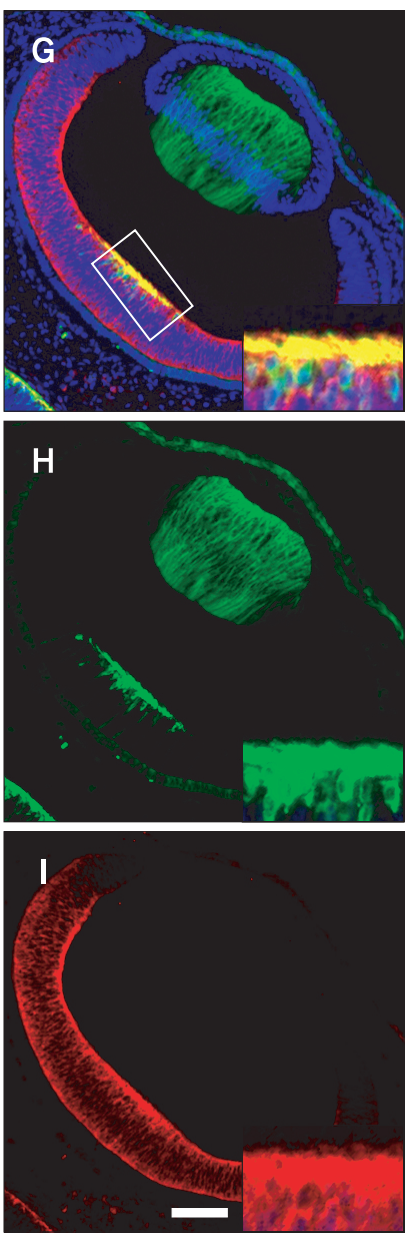

Fig. 2. Double immunofluorescence labeling of doublecortin (DCX) (red) with Pax6 (A-C), Islet 1 (D-F) and Tuj 1 (G-I). Inset show large magnification view of inner layer of central retina (boxes area). Scale Bar $=50 \mu \mathrm{m}$. 
Islet 1/DCX
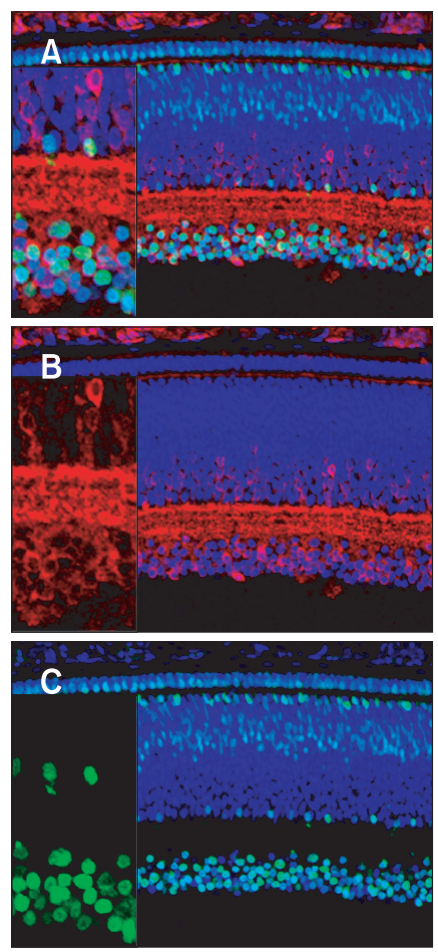

Tuj 1/DCX
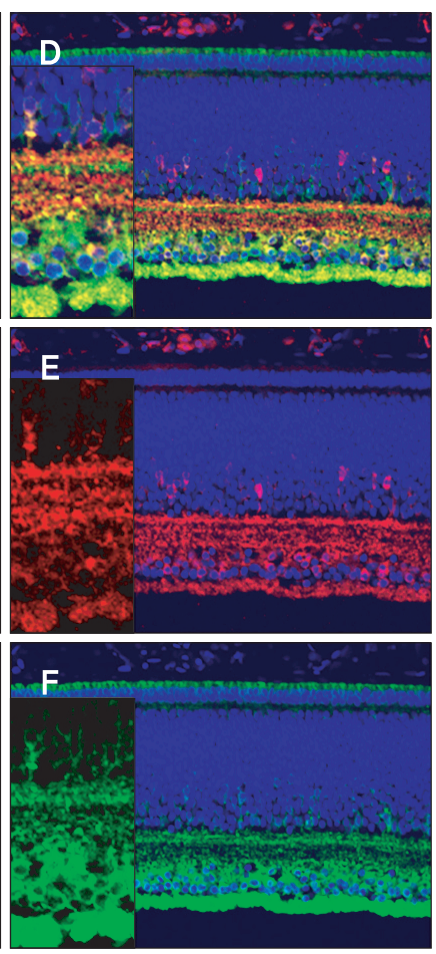

Neu N/DCX
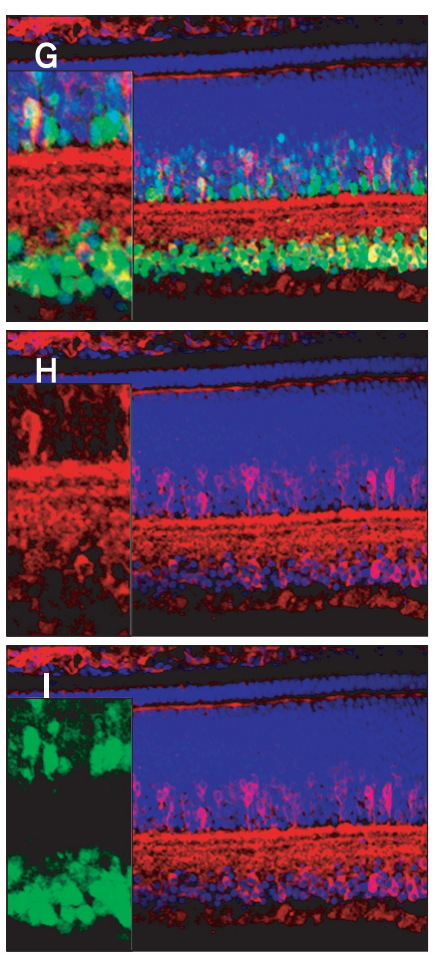

MAP 2/DCX
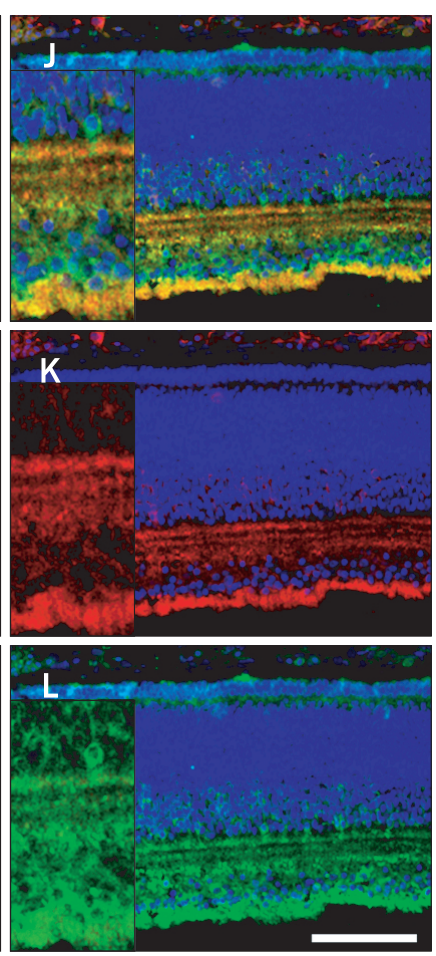

Fig. 3. Distribution of DCX in the E12 chick retina DCX and Islet 1 (A-C), Tuj 1 (D-F), Neu N (G-I), and MAP 2 (J-L) were double labeled. Scale Bar=50 $\mu$ m. DCX, doublecortin.

marginal, this result may indicate that DCX positive signals in the IPL could be derived from cells in the INL.

$\mathrm{Neu} \mathrm{N}$ is a neuronal marker, and labels both ganglion cells and a subset of horizontal cells in the rat. Therefore, we examined its co-labeling patterns with DCX, and we found many double-labeled cells. Furthermore, MAP 2, which labels dendritic processes, was nicely merged with DCXimmunoreactivity in the IPL. These results indicate that at least two cell types, ganglion cells and horizontal cells, express DCX in the E12 chick retina.

\section{DISCUSSION}

In this study, we found that DCX is expressed in the developing chick retina. In particluar, DCX expression was strong in the neural progenitor cells on E3, a time when brain neural progenitors did not express DCX (data not shown). To our knowledge, we think that our current observations are probably the first to show that DCX can be expressed in early progenitor cells before their specification into neuroblasts, in any brain regions in any species. On E3 in the chick, firstborne ganglion cells began to be produced, and they localized at the innermost region of the central retina.

Pax6 is a marker for neural progenitors in the retina, and was expressed in the peripheral region of the retina, where most cells were found to express DCX. In this respect, those Pax6 and DCX double-labeled cells are represent the immature and multipotent neural progenitors. Different from our current observation, such immunorectivity was not observed in the rat retina, suggesting that our current observation is species-specific. However, we could not completely rule out the possibility that the DCX antibody we used in this study cross-reacted with other chick-specific proteins expressed in the Pax6-expressing retinal progenitors. In fact, chicks also express DCX-like protein (DCXL), which is also expressed in the developing chick brain (Capes-Davis et al., 2005). Further studies on the specificity of our results and the expression patterns of other proteins of the same family member will help clarify this issue.

Recent evidence suggests that DCX-expressing cells produce non-neuronal cells such as oligodendrocytes in the rat; however, this has not been explored in detail (Weiss et al, 1996; Seaberg \& van der Kooy, 2003). This finding suggests that when cells begin to express DCX, they have not yet been fully predetermined as neuroblasts, and they can produce non-neuronal cells. In this respect, it appears that DCX is not an ultimate marker for neuroblasts in many brain regions and many different species.

On E12, we found that at least two different populations of retinal cells express DCX in the chick. Retinal ganglion cells 
express DCX in the developing chick retina. Similar results were found in the rat, indicating that this type of cells in two different species expresses DCX in a conserved manner. Another population of cells expressing DCX is the horizontal cells. In the rat, it has been reported that horizontal retinal cells express DCX (Lee et al., 2003), More interestingly, adult rat retina also showed DCX expression in the horizontal cells (Engelhardt et al., 2005). Although we did not examine whether adult chick retina also exhibited DCX expression in the horizontal cells, these results suggest that DCX is expressed specifically in horizontal cells in both species. Considering that other retinal cells such as photoreceptors and amacrine cells are also derived from neural progenitor cells, and these cells do not express DCX. It seems likely that the expression of DCX in chick retina is cell-type specific, and its cell-stage specificity is less clear.

\section{CONCLUSIONS}

We found that retinal neural progenitors in the early embryonic stage of the chick also expressed DCX, as do developing ganglion cells and horizontal cells in later stages of development. Our current observations suggest a potential role of DCX in neural progenitors.

\section{REFERENCES}

Cheek T F and Chen D (1988) Dislocation reduction on SIMOX substrates by using multiple implants. MRS Proceedings 107, 53.

Crean G M, Lyncrt S, Greef R, Stoemenos J, Rossow U, and Richter W (1992) Feasibility of SIMOX material quality determination using spectroellipsometry: comparison with Raman and planar view transmission electron microscopy. MRS Proceedings 235, 139.

El-Ghor M K, Pennycook S J, Namavar F, and Karam N H (1990) Formation of low dislocation density silicon-on-insulator by a single implantation and annealing. Appl. Phy. Lett. 57, 156.

Hill D, Fraudorf $P$, and Fraudorf G (1988) The reduction of dislocations in oxygen implanted silicon-on-insulator layers by sequential implantation and annealing. J. Appl. Phys. 63, 4922.

Hirth J P and Lothe J (1982) Theory of Dislocations (Wiley, New York).

Lee J D, Park J C, Venables D, Krause S J, and Roitman P (1993) Stacking fault pyramid formation and energetics in silicon-on-insulator material formed by multiple cycles of oxygen implantation and annealing. Appl. Phys. Lett. 63, 3330.

Margail J, Stoemenos J, Jaussaud C, and Bruel M (1989) Reduced defect density in silicon-on-insulator structures formed by oxygen implantation in two steps. Appl. Phys. Lett. 54, 526.

Ou X, Kogler R, Skorupa W, Moller W, Wang X, and Gerlach J W (2009) Gettering layer for oxygen accumulation in the initial stage of SIMOX processing. Nucl. Instr. Meth. B 267, 1273-1276.

Sears K, Wong-Leung J, Tan H H, and Jagadish C (2006) A transmission electron microscopy study of defects formed through the capping layer of self-assembled InAs/GaAs quantum dot samples. J. Appl. Phys. 99, 113503.

Park J C, Lee J D, Venables D, Krause S, and Roitman P (1992) Role of oxygen precipitation processes in defect formation and evolution in oxygen implanted silicon-on-insulator material. MRS Proceedings 279, 153.

van Ommen A H (1988) Low dislocation SOI by oxygen implantation. MRS Proceedings 107, 43.

Venables D, Jones K S, and Namavar F (1992) Low-dislocation-density silicon-on-insulator material produced by sequential oxygen implantation and low-temperature annealing. Appl. Phys. Lett. 60, 3147. 